\title{
An Overview on Development of Countermeasures for Breakwater against Earthquake and Tsunami Induced Damage
}

\author{
Chaudhary $\mathrm{B}^{1 *}$ and Hazarika $\mathrm{H}^{2}$ \\ ${ }^{1}$ Division of Environmental Science and Technology, Kyoto University, Japan \\ ${ }^{2}$ Department of Civil Engineering, Kyushu University, Japan
}

Submission: May 15, 2017 ; Published: June 07, 2017

*Corresponding author: Babloo Chaudhary, Research Associate, Division of Environmental Science and Technology, Kyoto University, Kyoto, Japan 606-8502, Tel: +81-75-753-6151; Fax: +81-75-753-6346; Email: babloomit@gmail.com

\begin{abstract}
The compound disaster triggered by earthquake and tsunami imposes devastating damage to structures and human lives living near seacoasts. In past few years, breakwaters (which are used to protect coastal areas from devastating damage of tsunamis) failed during tsunami. It led to enter the tsunami waves into the coastal areas, and created deep devastation there. It was observed that the breakwaters collapsed mainly due to failure of their foundations. Recently, some research works have been done to make breakwater resilient against tsunami induced damaged in order to protect coastal areas from devastating damage of tsunami. This paper mainly reviews some recent studies towards making the breakwater resilient against earthquake and tsunami induced damage
\end{abstract}

Keywords: Breakwater; Counter measures; Earthquake; Foundation; Stability; Tsunami

\section{Introduction}

Breakwater is an artificial offshore structure which is commonly constructed to protect port and harbor from destructive effects of sea waves, currents, typhoons and tsunamis by reflecting and dissipating their wave energies. It creates sufficient calm water for safe navigation, anchorage of vessels, loading and unloading of cargoes and other harbor activities. In recent few decades, more marine infrastructures, such as breakwaters, are either constructed or extended due to increase in economic activities. Composite breakwater is widely used in the world due to its advantages such as ease of construction, economic and suitability for deeper sea. As breakwater rests on seabed (Figure 1), so it is susceptible to damage during earthquake and tsunami. The devastating damage of offshore structures (e.g. quay walls, breakwaters) has been recorded during to the past earthquakes in Los Angeles (USA) in 1994, Kobe (Japan) in 1995, Kocaeli (Turkey) in 1999, Athens (Greece) in 1999, Sumatra (Indonesia) in 2004 and Tohoku (Japan) in 2011. Moreover, tsunami is a big challenge for stability of breakwaters, and several coastal structures (including breakwaters) failed during past earthquakes and tsunamis such as the 2004 Indian Ocean earthquake and the
2011 off the Pacific cost of Tohoku earthquake and subsequent tsunamis [1-6]. The classic example of failure of breakwater is collapse of the world's deepest breakwater at Kamaishi port, Japan during the 2011 off the Pacific coast of Tohoku earthquake and tsunami. The earthquake was the most powerful earthquake ever hit Japan, and triggered powerful tsunami waves that reached height up to 40.5 meters in Miyako area (Iwate Prefecture), and travelled up to $10 \mathrm{~km}$ inland (Sendai). Due to failure of the breakwater, tsunami entered in Kamaishi port, and led to catastrophic losses for population and structures. The breakwater was failed mainly due to collapse of its foundation. There are some other breakwaters in Japan such as Hattaro Breakwater in Hachinohe Port and breakwater at Onagawa Port which were also damaged mainly due to failure of their mounds during the 2011 earthquake and tsunami. The damage to the mounds was more significant than to the main bodies of these breakwaters. Failure of the breakwaters led to enter the tsunami waves in the coastal areas, and the tsunami waves created deep devastation there. Therefore, stability of breakwaters is very important for safety of structures and population living near seacoasts during natural disaster such as tsunami. 


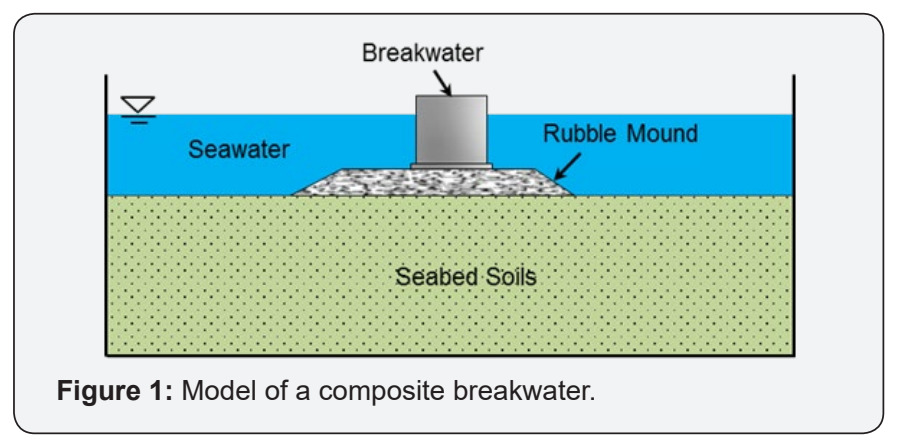

Breakwater under Actions of Earthquake and Tsunami

The observed damage of coastal structures and lives due to failure of breakwaters raised the importance of development of earthquake and tsunami resistant foundation for breakwater in order to provide safety for structures and human lives in coastal areas. To develop countermeasures, it is important to determine the behavior of breakwater foundation under actions of earthquake and tsunami. Actually, tsunami is often triggered by a strong earth quake and tsunami strikes within a small time interval after the earthquake. Coastal structures are hit by both earthquake and tsunami within a small time interval, and may get damaged due to earthquake in addition to tsunami. To the end, Chaudhary et al. [7] described the factors which are responsible for failure of breakwater during earthquake and tsunami, and conducted analytical study to determine the stability of breakwater subjected to earthquake and tsunami. Experimental study is also needed to understand the failure process of breakwater foundation during earthquake and tsunami. Therefore, Hazarika et al. [810] conducted a series of physical model tests to make clear the behavior of breakwater foundation under earthquake and tsunami. It was observed that in addition to tsunami, earthquake (that precedes tsunami) imposed instability to breakwater. Significant damage of foundation ground was observed during earthquake which led to excessive seismic subsidence and large horizontal displacement of breakwater. During tsunami, tsunami impact forces on breakwater, scouring of rubble mound and seepage were main reasons of failure of breakwater. Matsuda et al. [11] performed numerical analyses to understand the stability of breakwater foundation under earthquake and tsunami. Liquefaction occurred in foundation ground due to strong earthquake motions which led to more than $1 \mathrm{~m}$ seismic subsidence of breakwater. Hence, for effective countermeasures against tsunami, the countermeasures should be effective against earthquake (that precedes tsunami) along with tsunami.

\section{Countermeasures for Foundation of Breakwater}

Recently, some efforts have been made to develop countermeasures for foundation of breakwater in order to make it resilient against damage caused by compound disaster triggered by earthquake and tsunami. Kikuchi et al. [12] suggested a reinforced foundation using steel walls into foundation ground behind caisson. They developed the reinforced foundation to mitigate tsunami induced damage of breakwater. Tsujio et al. [13] described effects of increased width of mound to reduce possibility of failure due to lateral displacement of breakwater caused by tsunami impact forces. Concrete blocks were put behind breakwater by Takahashi et al. [14] to enhance stability of breakwater against tsunami. As countermeasures, filter units were used to cover rubble mound by Mitsui et al. [15] for stability of breakwater. Seepage beneath breakwater is a reason of failure during tsunami, therefore Ueda et al. [16] covered seaside rubble mound by rubber membrane to prevent such seepage. All these countermeasures were developing to increase the stability of breakwater foundation against tsunami. On the other hand, to enhance stability of breakwater during earthquakes, Chaudhary et al. [17-19] developed reinforcing countermeasures for foundation of a breakwater, and described their effectiveness against different earthquake loadings.

\section{Conclusion}

This paper summarizes some of the recent research works which were conducted to develop countermeasures for foundation of a breakwater in order to make it resilient against the damage caused by earthquake and tsunami. Based on the studies, conclusions are given as below

A. The earthquake that precedes tsunami may impose significant damage to breakwater. Excess seismic subsidence of breakwater was observed due to strong earthquake. Hence to develop countermeasures, it is important that the countermeasures should be effective against earthquake along with tsunami induce damage. Some countermeasures have been developed by the researchers for providing resiliency to breakwater against earthquake induced damage.

B. Tsunami impact forces, scouring of mound and seepage beneath breakwater were main reasons of failure of breakwater during tsunami. Countermeasures were suggested to enhance the stability of breakwater foundation during tsunami.

C. Further study is needed to develop countermeasures for breakwater foundation which can mitigate the damage caused by both the earthquake and tsunami induced forces.

\section{References}

1. Hazarika H, Kasama K, Suetsugu D, Kataoka S, Yasufuku N, et al. (2013) Damage to geotechnical structures in waterfront areas of northern Tohoku due to the march 11, 2011 tsunami disaster. Indian Geotechnical Journal 43(2): 137-152. 
2. Hazarika H, Kataoka S, Kasama K, Kaneko K, Suetsugu D, et al. (2012) Composite ground disasters caused by the earthquake and tsunami in Aomori, Iwate Prefecture, northern. Japanese Geotechnical Engineering Journal, Special Issue on 2011 Great East Japan Earthquake 7(1): 1323.

3. Hara T, Ohkawar M, Ohsum T, Yamanaka M, Ishihara Y, et al. (2012) Damage of southern central part of coastal region of Iwate prefecture due to off the Pacific Coast of Tohoku Earthquake. Geotechnical Engineering Magazine, Japanese Geotechnical Society 7: 25-36.

4. Takahashi S, Kuriyama Y, Takashi T, Kawai Y, Arikawa T, et al. (2011) Urgent survey for 2011 Great East Japan earthquake and tsunami disaster in ports and coasts part I (tsunami). Technical note 1231, Port and Airport Research Institute, Japan, pp. 1-9.

5. Sugano T, Nozu A, Kohama E, Shimosaka KI, Kikuchi Y, et al. (2014) Damage to coastal structures. Soils and Foundations 54(4): 883-901.

6. Kazama M, Noda T (2012) Damage statistics (Summary of the 2011 off the Pacific Coast of Tohoku Earthquake damage). Soils and Foundations 52(5): 780-792.

7. Chaudhary B, Hazarika H, Ishibashi I, Abdullah A (2017) Sliding and overturning stability of breakwater under combined effect of earthquake and tsunami. Ocean Engineering 136: 106-116.

8. Hazarika H, Chaudhary B, Nishimura K, Kasama K, Noda T, et al. (2015) Physical and numerical modeling of resilient breakwater foundation subjected to earthquake and tsunami. In: Proceedings of the $50^{\text {th }}$ Indian Geotechnical Conference, Pune, India.

9. Hazarika H, Chaudhary B, Monji N, Ishikura R, Kasama K, et al. (2015) Resilient breakwater foundation against level II earthquake and tsunami. In: Proceedings of $6^{\text {th }}$ International Geotechnical Symposium on Disaster Mitigation in Special Geo environmental Conditions, Chennai, India pp. 35-46.

10. Hazarika H, Hara T, Nishimura K, Yamasaki N, Monji N, et al. (2016) Fundamental study on seismic resistant behavior of caisson type breakwater foundation reinforced by steel sheet pile and gabion. Journal of Japan Association for Earthquake Engineering 16(1): 184 204.
11. Matsuda T, Maeda K, Miyake M, Miyamoto J, Sumida H, et al. (2016) Instability of a Caisson-Type Breakwater Induced by an EarthquakeTsunami Event. Int J Geomech 16(5): 1-10.

12. Kikuchi Y, Kawabe S, Takaenaka S, Moriyasu S (2015) Horizontal loading experiments on reinforced gravity type breakwater with steel walls. Japanese Geotechnical Society Special Publication (the 15th Asian Regional Conference, Fukuoka, Japan) 2(35): 1267-1272.

13. Tsujio D, Yasuda T, Mase H, Mori N, Maeda K, et al. (2013) Experimental study on effects of reinforcement for caisson breakwater against abnormal tsunami. Journal of Japan Society of Civil Engineers, Ocean Engineering Ser. B3, 69 (2): I_473-I_478.

14. Takahashi H, Sassa S, Morikawa Y, Takano D, Aoki R, et al. (2014) Centrifuge tests on resistance force of breakwaters reinforced by embankment. Journal of Japan Society of Civil Engineers, Ocean Engineering Ser. B3, 70(2): I_870-I_875

15. Mitsui J, Matsumoto A, Hanzawa M, Koyama H, Shinomura Y, et al. (2013) Effective methods for covering breakwater rubble mounds against tsunami using filter units. Journal of Japan Society of Civil Engineers, Ocean Engineering Ser. B3, 69(2): I_479-I_484.

16. Ueda K, Iai S, Tobita T (2016) Centrifuge model tests and large deformation analyses of a breakwater subject to combined effects of tsunami. Soil Dynamics and Earthquake Engineering 91: 294-303.

17. Chaudhary B, Hazarika H, Nishimura K (2017) Effects of duration and acceleration level of earthquake ground motion on the behavior of unreinforced and reinforced breakwater foundation. Soil Dynamics and Earthquake Engineering 98: 24-37.

18. Chaudhary B, Hazarika H, Pasha SMK (2017) Countermeasures for breakwater foundation subjected to foreshocks and main shock of earthquake loading. Marine Georesources \& Geotechnology, pp. 1-15.

19. Chaudhary B, Hazarika H, Nishimura K (2016) Effects of reinforcement on the performance of breakwater foundation subjected to earthquake loadings. International journal of geotechnical Engineering 11(2): 186197.

\section{Your next submission with Juniper Publishers} will reach you the below assets

- Quality Editorial service

- Swift Peer Review

- Reprints availability

- E-prints Service

- Manuscript Podcast for convenient understanding

- Global attainment for your research

- Manuscript accessibility in different formats

(Pdf, E-pub, Full Text, Audio)

- Unceasing customer service

Track the below URL for one-step submission https://juniperpublishers.com/online-submission.php 